\title{
The GTTP Movement: Engaging young minds to the beauty of science and space exploration
}

\author{
Rosa Doran \\ NUCLIO - Núclio Interactvivo de Astronomia \\ Largo dos Topázios, 48, 3 Frt, 2785-817 S. D. Rana, Portugal
}

\begin{abstract}
The Galileo Teacher Training Program (GTTP) is a living legacy of IYA2009. As a cornerstone of this important moment in the history of Astronomy, GTTP has managed to name representatives in over 100 nations and reached over 15000 teachers at a global level. The model used so far ensures sustainability and a fast growing support network. The task at hand is to engage educators in the use of modern tools for science teaching. Building the classroom of tomorrow is a promising path to engage young minds to the beauty of science and space exploration.
\end{abstract}

Keywords. Miscellaneous, sociology of astronomy

The mission assigned to GTTP during IYA2009 was to train teachers in the use of astronomy tools and existing resources that are freely available on the internet and its transfer into classroom science curricula; the range of activities varying from cutting edge digital tools to hand-on experiments with readily available materials. The model adopted to build the network was the cascade effect, where teachers train other teachers and are building blocks of a strong and sustainable structure. Having reached over 100 nations and 15000 educators worldwide the challenge lies now in the continuity of efforts.

The philosophy adopted puts teachers at the heart of what we do. The training events are just the first step on the joint road. Continuous support, new resources, promotion of contests and campaigns are examples of stimulus offered to those entering the network. Collaboration with other existing programs is key to the continuation and strength of GTTP. As examples we can name:

- The use of the radio antennas being constructed by the European Hands-on Universe;

- Participation in the International Astronomical Search Collaboration programs where students learn science while working on real research, a Global Hands-on Universe partner project;

- Participation in European Research projects such as: Discover the Cosmos, Open Discovery Space and Go-lab (European Commission funded projects);

- Promotion of joint projects with Dark Skies Awareness, Astronomers without borders, TWAN, UNAWE, GalileoMobile, to name a few;

A strong social powered communication effort is also an investment taking place in GTTP by the use of channels such as social network platforms, newsletter, youtube channel, etc. Reaching nations equally is a concern and the introduction of eTraining lessons, promotion of eScience cafes, or the preparation of e-lessons are plans being structured for the near future.

GTTP lives as a legacy of IYA2009 and is now part of IAU Strategic Plan for the Developing World. The road ahead is of continuous construction and strengthening of the blocks being built so far. 